In applying and developing the law the courts may be able to create and improve standards and to impose effective sanctions in appropriate cases. The public is rightly concerned with the dignity of the patient and the social desirability of compensation for the injured, hence the growing demand for some form of no-fault compensation. Instead of a forensic battle between the injured patient seeking compensation and the doctor seeking to protect his reputation and prestige, we need a system that both compensates the patient and protects the doctor from unfortunate attack upon his professional skill (subject to error though he is, like all of us).

The doctrine that the doctor knows best, indeed that only the doctor knows, that it is a matter solely within the clinical skill and judgement of the doctor, still largely survives. $\mathrm{He} / \mathrm{she}$ will decide whether a child shall be supplied with contraception; who shall be selected for kidney transplant; whether to apply chemotherapy; whether or not to keep the patient alive. In the United States of America the courts have intervened in such matters more readily and more decisively than in other countries.

A worrying new development, or rather discovery, is iatrogenic disease or illness caused or induced by the process of medical examination or treatment, for example radiography and drugs.

Incidentally, the effect or impact of medicine can perhaps be exaggerated. The quality of life has not improved that much. Life expectancy has barely increased. Heart disease and cancer are major unconquered causes of death.

It may be that we are facing a forensic crisis. The medical profession work in isolation, close ranks, maintain a conspiracy of silence, refuse to disclose what happened. The patient is largely powerless. In the adversarial system, each party, plaintiff and defendant, seeks for the expert witness favourable to his side, who will reject the unfavourable, so that in court the witness, expert though he may be, is seen as partisan, biassed, lacking in objectivity, a witness to be treated with scepticism. Where is the truly independent expert witness? Where is the well-qualified judge able competently and objectively and fairly to evaluate the evidence?

Professor Dieter Giesen is a scholar of high order. His mastery of the issues, his lucid exposition, and his enormous range of source material are most impressive. In addition to the discussion of these, and many other ethical problems, he has written at length and in depth on the civil liability of physicians and civil liability with regard to new methods of treatment and experimentation. The comparative material from the English-speaking world and from the continent of Europe, and indeed elsewhere, also marks out this study as of particular value.

ALEC SAMUELS

$\mathcal{F P}$, Barrister, BA (Cantab)

\section{Ethics, Technology and Medicine}

Edited by David Braine and Harry

Lesser, 138 pages, Aldershot, $£ 19.50$, hbk, Gower Publishing Company Limited, 1988

This is a difficult book for a mere doctor. Not only is the typesetting small and closely packed, the introduction, with its unsubstantiated implication that medicine has adopted a wholly 'technical attitude', implies a rather biased view. In addition the title and the book's claim to be '.... a response to the moral problems caused by a rapid growth of technology in medicine and psychotherapy...', created an expectation that was never really fulfilled. There was relatively little specific reference to technology and the ultimate frustration came in David Lamb's statement when he was exploring the moral dilemma arising from the opportunity cost (although he did not acknowledge the opportunity lost to another potential patient) of extending the life of a single patient at some significant financial cost. He claimed '...It is not the task of moral philosophers to alleviate moral anxiety with references to economic reality; it is not their task to relieve moral anxiety at all'. Perhaps this is why I was frustrated by the various allegations throughout the book about doctors and their explicit and implicit intentions. Given that modern technology does indeed create moral problems, and that these are recognised by many doctors, I was searching for constructive help from the moral philosophers: at the very least I looked for some help in formulating the frameworks within which moral decisions can be made.

Despite my overall frustration this book did indeed provide some thoughtful direction although not in the areas I had expected. It is a series of essays beginning with a complex analysis by David Braine of 'Human Animality'. Simon Glen's contribution on 'Objectivity and Alienation' identifies the obscene disparity between current human knowledge and technological capacity and the resultant threats to survival from widespread starvation, resource depletion, pollution and nuclear weaponry. He identifies man's increasing alienation from his roots and his failure to 'be-inthe-world with others' which results in a hedonistic merry-go-round of getting and spending. Harry Lesser's 'Technology and Medicine: Means and Ends' identifies the vastly increased scope of medical practice and the resultant change in expectations of both doctors and patients. This essay is better at identifying that doctors differ in their approaches but I was confused by his restriction of 'medicine' to mean the 'removal of undesirable physical conditions' followed by a later condemnation of such a limited approach. The task of helping people/ patients to understand themselves and their relations with others is something different which he defines as 'counselling'. This seems to destroy the argument for holistic medicine thatê must embrace both.

John Hostler's 'The Sanctity of Life and the Sanctity of Death' emphasises the importance of allowing patients to know and prepare themselves for death; David Lamb's 'Down the Slippery Slope' ranges from Nazi eugenic killings to cost/benefit issues and warns how the 'cunning of reason' can create a thin end of the wedge for a gradual change in the moral climate within which decisions are made. Ruth Chadwick's and Heather Draper's helpful contributions on 'Genetic Improvement' and 'Transexuals and Werewolves' respectively, are the only essays that specifically address the ethical issues raised by our modern and future technological capacity in medical practice. David Linton explores 'Why is Pornography Offensive?' which is interesting but I'm not sure why it is here and David Smail finishes with 'Technology and Psychotherapy' in which he explains that technology plays a minimal role. Indeed he emphasises that a 'magical' technological response, capable of alleviating human distress, is highly unlikely and the book concludes with his salutory reminder that psychological damage will only be avoided 'through our developing a society in which we treat each other with greater care and kindness'. 
DR HELEN ZEALLEY Chief Administrative Medical Officer Lothian Health Board Edinburgh

\section{Health Care Systems}

Edited by Hans-Martin Sass and

Robert O Massey, 368 pages, Dordrecht, £44.50, hbk, Kluwer, 1988

The aim of this volume is to get beyond issues of cost containment to the 'basic moral and cultural roots' of health systems and to ask how systems might be reconstructed so as to fit values. This quest started at an international symposium in West Germany in 1985.

Papers by Englehardt and Sass set the scene promisingly. Sass wants to see the individual citizen play a larger role in caring for his or her health "for moral and cultural reasons, not primarily for economic reasons'. He wants to see costs and benefits of health programmes re-defined to cover costs in terms of loss of autonomy and benefits in public risk management and he sets out a framework for making choices at the margin. The Sass preferred choice would seem to be that government should concentrate on basic insurance medicine (BIM).

Detailed contributions on national health systems follow. Unfortunately, little use is made of the Sass framework. The day-to-day management of health systems seems to show a diminished concern for equity and access. The French experience with the end of ideology seems fairly typical. As Lacronique sums it up: 'It would be hard to find a single article advocating health policy in terms other than those which reflect a spirit of "real-politik" where any tribute to cost containment is passively accepted'. In the Netherlands 'budget cuts are necessary because of lack of funds', and although the Netherlands is said to have broken through to the higher perception that 'more health care expenditure does not necessarily result in improved health', it is not clear what effect if any this has had on policy.

The freshest contribution is by Feshbach on health in the USSR where use of performance indicators in hospital mortality rates discourages hospitals from admitting patients with a poor prognosis. Maynard makes some constructive suggestions for more information on costs, qualities and quantities as a prerequisite of any serious ethical debate at all. Delkeskamp-Hayes takes issue with Anglo-Saxon welfare economics in its use of altruism as grounds for collectivism.

The last sections cover microdecisions and philosophic principles but without managing to relate them very effectively. Viekhues contributes a vigorous essay against compulsion in prevention.

The book is most useful in providing contributions written from the standpoint of European individualism. Such individualism seems to have roots in Kant rather than in Adam Smith and at the moment seems to lack any real purchase on the pragmatic decisions taken by policy-makers in health systems. Individualism without market economics seems doomed to be a private and rather sketchy vision.

NICK BOSANQUET Professor of Health Policy University of London Egham Hill, Egham Surrey, TW20 OEX

\section{New Reproductive Techniques: A Legal Perspective}

Douglas J Cusine, 276 pages,
Aldershot, £25, hbk, Gower, 1988

Douglas Cusine has for a long time been a contributor to the debate on the legal issues of donor insemination. In this book he lucidly lays out the complexity of the legal pitfalls surrounding assisted conception, drawing particularly on the greater experience of donor insemination.

Two things strike me on reading this book. First, how naively we enter into treatment with donor gametes and embryos, usually not recognising the complex situations that may arise. There is such a strong assumption that all parties are acting in good faith that we find it difficult to anticipate that problems could occur in years to come. Presumably too, as family relationships become more tangled, this area is going to become even more fraught. All of us working in this field should clearly be aware of the consequences of our involvement, not only to protect ourselves, but particularly to ensure that the children conceived as a result of our intervention are adequately cared for.

Secondly, I was made aware that such laws as exist today in the field of assisted conception depend in the main part on case law. This leads to such anomalies as two more or less identical cases being judged in diametrically opposed directions. I was also shocked by the subjectivity of some of the judges, where summings-up are quoted in the book. Moral disapproval is clearly registered in some of the extracts and it becomes clear that current moral stances strongly influence judgements when there is no statute designed specifically to cover a complex situation.

It is obviously time to clarify the legal issues that arise from gamete and embryo donation, surrogacy and embryo research. Mr Cusine provides a comprehensive review of the Warnock Committee's report which addressed these issues and also draws attention to some situations that it did not cover satisfactorily. It was expected that the White Paper on Human Fertilisation and Embryology prepared in 1987, and drawing heavily on the findings of the Warnock Committee, would have been discussed in Parliament by now, but at the time of writing, this appears to have been shelved.

Mr Cusine has written an excellent summary of the legal issues raised by the new reproductive techniques. His book also contains a useful bibliography. I shall find it a helpful guide as I contemplate counselling couples for donor insemination and in vitro fertilisation.

RUTH CURSON
Subfertility Clinic
King's College Hospital, London

\section{Confronting Death}

Richard W. Momeyer, 182 pages, Bloomington, Indianapolis, USA, $\$ 25.00 \mathrm{hbk}$, Indiana University Press, 1988

Confronting Death is a book written by a philosopher about attitudes to death. It is divided into two parts. The first part is about general attitudes to death, and by implication, to life also, and discusses the concept of 'good dying'. The second part builds upon this to consider specific problems, including suicide and the management of patients not in a position to make their own wishes clear.

The title is itself controversial in that accepting death is more generally advocated than confronting it. The 